\title{
Locus of control moderates the relationship between headache pain and depression
}

\author{
Robin L. Heath · Matilda Saliba · Oula Mahmassani · \\ Stella C. Major · Brigitte A. Khoury
}

Received: 28 May 2008/Accepted: 3 July 2008/Published online: 5 August 2008

(C) Springer-Verlag 2008

\begin{abstract}
The aim of the current study was to triangulate qualitative and quantitative data in order to examine in greater detail the relationship between self-reported headache pain severity, depression and coping styles. Psychosocial scales, headache characteristic scales and indepth interviews were administered to 71 adults with the diagnosis of primary headache. Regression analyses with the scales showed that greater self-reported headache pain severity was associated with higher levels of depression. A high internal locus of control weakened the relationship between the headache severity and depression variables. The qualitative data supported the relationship between pain severity and internal locus of control and, in addition, revealed that perceived efficacy of pharmacologic intervention might be a related factor. The results suggested that stronger coping skills might reduce depression among headache sufferers.
\end{abstract}

Keywords Self-efficacy · Locus of control · Depression . Headache

R. L. Heath $(\bowtie) \cdot M$. Saliba

Faculty of Health Sciences, American University of Beirut, P. O. Box 11-0236, Riad El Solh, Beirut 1107 2020, Lebanon e-mail: rlheath@aub.edu.lb

\section{O. Mahmassani}

Faculty of Medical Sciences, Newcastle University, Newcastle, UK

S. C. Major

Primary Care Education, Imperial College, London, UK

B. A. Khoury

Department of Psychiatry, American University Hospital, Beirut, Lebanon

\section{Introduction}

The study of primary headache is overwhelmingly quantitative, with researchers selecting from biomedical, epidemiological, or psychosocial metric models. Qualitative studies focusing on the patients' experience and perceptions of headache increasingly are being conducted [1-8]. All the designs provide useful information for documenting the burden of headache and informing treatment plans, however, these models individually offer only a partial insight into the phenomenon. Few studies on headache have been conducted in the Eastern Mediterranean region, and those that have been done focused on prevalence [9-11]. The aim of the current study was to triangulate qualitative and quantitative data in order to obtain a more holistic picture of the relationship between self-reported headache pain severity and psychosocial factors among headache patients in a university community in Beirut, Lebanon.

Studies have found psychiatric comorbities associated with migraine without aura compared to healthy controls [12] and distinctions between headache types with respect to psychopathology [13]. Other research has found differences in personality traits between migraineurs and healthy controls [14] and increased depression and anxiety among migraineurs with aura as opposed to migraineurs without aura [15]. The relationships among headache etiology, stress, coping styles and psychological factors have been addressed in a number of ways. One stream of research focuses on predisposing factors such as comorbid psychopathology or personality types, which are used to explain the elevated levels of psychological symptoms observed among headache patients [12-20]. Although Sternbach and colleagues [21] found psychological differences between headache types, the authors concluded that the differences likely were due to the frequency and duration of pain-free 
intervals, that is, psychological symptoms might be the result of living with recurrent pain rather than the cause of the pain.

Another line of research focuses on the role of cognitive factors as intervening between headache pain and illness coping strategies. Previous research suggested that selfefficacy and locus of control underpinned illness coping strategies and modified a variety of clinical outcomes including headache-related disability, stress, health seeking behavior, chronification of tension-type headaches and pain perception [21-30]. Increased self-efficacy were associated with positive headache coping strategies [23]. Self-efficacy has been shown to be a buffer between the frequency of stressful life events and the frequency of headache attacks [24]. When headache severity was controlled, higher levels of self-efficacy were associated with lower levels of anxiety [23]. Further, lower self-efficacy modified the effect of an intervention, written emotional disclosure, on a health measure [31]. Previous research has shown that locus of control influenced treatment outcome and headache-related disability [23, 25, 26, 33].

In light of the evidence for the association of psychopathology with migraine and tension-type headaches [12, 13, 20] and findings for the role of cognitive factors in moderating the impact of headache pain [21-30], we hypothesized that: (1) a greater degree of depression would be associated with a greater severity of headache pain and (2) coping styles, as represented by the self-efficacy and locus of control variables, would modify the association between depression and headache pain severity (see Fig. 1). We anticipated that the qualitative portion of the study would reflect the hypothesis, that is, participants with more severe headache pain would be more likely to voice depressive symptoms and ineffectual coping skills compared to those with less severe pain. Further, the illness narrative would provide an insight as to how pain and coping skills interact in the context of the individual experience of headache.

\section{Methods}

Participants

Participants were recruited from a primary care health center on campus at the American University of Beirut.

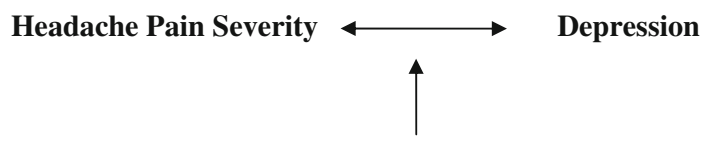

Coping Styles

Internal locus of control

Self efficacy

Fig. 1 Conceptual framework
Students, faculty, staff and their families utilize the university health care center. An appointment with a doctor entails a minimal fee of 2.00 USD. National regulation of pharmaceuticals, including analgesics, is just beginning in Lebanon. Drugs that would be available only by prescription in many countries are readily available without a prescription at pharmacies in Lebanon. A computerized list of all patients who had been diagnosed with primary headache over the previous 12 months was generated from the health center database. Invitations to participate in the study and contact information were sent by campus mail to all persons on the list. Participants were excluded from the study if they reported that they no longer had headaches, or had headache types other than migraine, tension-type, or mixed migraine and tension-type. Participants who met the inclusionary criteria and agreed to participate in the study signed a written informed consent form in the subjects' choice of English or Arabic. The Internal Review Board of the American University of Beirut approved the ethical treatment of the participants.

\section{Data collection}

All data were collected by co-author O.M. in her office in the participants' choice of English or Arabic. The three phases of the interview were administered in the following order: (1) psychosocial scales, (2) headache characteristics, and (3) in-depth semi-structured interviews on the participants' headache experiences.

\section{Psychosocial scales}

Psychosocial scales included the Beck Depression Inventory, Headache Specific Self-efficacy Scale and Headache Specific Locus of Control Scale [23, 24, 34]. The Headache Self-efficacy Scale is a 21-item, 5-point Likert-type scale that assesses the degree of confidence a person feels that he or she can prevent a moderately painful headache. The test score range is 0 for the highest self-efficacy and 250 for the lowest self-efficacy. For the purposes of the current study, the Headache Specific Self-efficacy Scale and Headache Specific Locus of Control Scale were translated into Arabic by co-author O.M., who is bilingual in Arabic and English.

The headache specific locus of control scale is a 33item, 5-point Likert-type scale that assesses the degree to which the individual believes that they themselves have control over their headaches (internal locus of control), headache episodes occur by chance (external locus of control), or that health care professional can control the individual's headache (professional locus of control). The ranges for the professional and external locus of control scales are a high of 55 and a low of 11. The highest internal locus of control is 50 and the lowest is 10 . 
The Beck Depression Inventory ranges from 0 for no depression to 63 for the greatest depression. The scoring is as follows: $0-9=$ normal, $10-15=$ mild depression, $16-$ $19=$ mild to moderate depression, $20-29=$ moderate to severe depression and 30-63 = severe depression [34]. The Arabic translation of the Beck Depression Inventory has undergone cross-cultural validation with the English version and is regular clinical use in the region [35].

Headache characteristics scales

Participants were asked to rate their headaches for duration, frequency and average intensity of pain on Likert-type scales. Duration was rated from 0 to 4 : less than $1,1-2,4 \mathrm{~h}$ to a day, and two to three days. Frequency was rated on a 0-4 scale: always, usually every day, three to four times a week, two times a week, and once a week or less. Average intensity of headache pain was rated from 0 to 4 : mild, mild to moderate, moderate, moderate to severe and severe. Participants were placed into one of five headache categories consistent with the criteria of the Headache Classification Committee of the International Headache Society [36]: migraine with aura, migraine without aura, episodic tension-type, chronic tension-type and mixed migraine and tension-type. Chronic tension-type headache was defined as a tension headache that occurs at least three to four times a week. Co-author S.M., a family physician at the American University of Beirut infirmary, reviewed the complete data from each participant to confirm that all were assigned to the correct headache type category in accordance with the Headache Classification Committee of the International Headache Society [36].

\section{Results}

We sent 326 invitation letters by campus mail. Twentyseven letters were returned because the addressees could not be located. Of the remaining 299 invitations, 74 individuals responded, which was a response rate of almost $25 \%$. Three individuals were excluded as they did not complete some of the scales, leaving 71 adult participants. Women composed just over half of the sample (54\%) and most of the participants were married $(68 \%)$. Seventy-six percent attained at least a High School education and the age range was 20-62 with a mean of 37.7 years $(\mathrm{SD}=11)$.

\section{Quantitative analysis}

Migraine without aura (26\%), chronic tension-type (24\%), and episodic tension (24\%) were the most common headache types, whereas migraine with aura (15\%) and mixed migraine and tension (19\%) were the least common. None
Table 1 Odds ratio for depression

\begin{tabular}{llll}
\hline & Model I & Model II & Model III \\
\hline Headache severity & $1.77^{*}$ & 1.43 & 1.45 \\
Self-efficacy & & 1.01 & 1.01 \\
Internal locus of control & & $0.89^{* *}$ & $0.91^{*}$ \\
Age & & & 1.04 \\
Education & & & 0.95 \\
Female & & & 2.20 \\
\hline
\end{tabular}

* Significant at $P<0.05, * *$ Significant at $P<0.01$

of the psychosocial or headache characteristic scores varied significantly by sex or by headache type.

Regression models were applied using Statistics Package for Social Sciences software program (SPSS version 14.0 for Windows) in order to examine the relationship between the headache pain severity (pain) and depression variables while taking into consideration psychosocial variables (see Table 1). Model I shows a significant association between greater levels of pain and greater levels of depression. After entering the coping styles variables, selfefficacy and locus of control in Model II, pain was no longer associated with depression. Lower levels of internal locus of control (ILOC) were significantly related to higher levels of depression whereas self-efficacy was not significant. Therefore, ILOC played a protective role with regard to depression among those who reported more severe headache pain. In Model III, the relationship between ILOC and depression persisted after controlling for age, education, and sex. Thus, our hypothesis that coping styles would influence the association of pain and depression proved to be correct only for ILOC.

\section{Qualitative analysis}

The semi-structured interviews ranged from $20 \mathrm{~min}$ to $2 \mathrm{~h}$ and averaged about an hour in length. The interview questions are shown in Table 2. A thematic analysis design was used to identify issues salient to the participants. The interviews were reviewed several times by co-authors R.H., M.S. and O.M. in order to establish crosscutting themes. Recurring themes were developed into a codebook by R.H., which research assistants then applied to the transcripts.

Table 2 Interview questions

\begin{tabular}{ll}
\hline 1 & Describe your headache and how it begins \\
2 & What do you do to relieve your headache \\
3 & What do you think causes your headache \\
4 & $\begin{array}{r}\text { How do your family, friends and work mates treat } \\
\text { you when you have a headache }\end{array}$ \\
5 & How do you feel about yourself as a headache patient \\
\hline
\end{tabular}


Ten percent of the transcripts were cross-coded to ensure the accuracy of the coding. The transcripts were entered into QSR NUD*IST6, a qualitative research package.

Overall, we found that our participants voiced self developed pain management strategies, an interference with day-to-day function and information seeking behavior. Some expressed disappointment with treatment given by doctors, avoidance of social events for fear of having a headache, the need for seclusion during headaches, positive family history and the priority of headache in participants' lives.

As internal locus of control (ILOC) proved to be a significant finding in the quantitative portion of the study, we used QSR NUD*IST6 to extract the theme of headache pain management from all the interviews, as this theme was likely to embody the locus of control concept. In order to identify more clearly the relationship between locus of control, headache pain severity and depression, we compared excerpts coded for headache pain management from interviews of ten participants who scored at the extremes on ILOC. Five interviews of participants that scored within the highest 10th percentile on ILOC were selected. One of the five participants in the lowest 10th percentile on the ILOC group made conflicting statements concerning headache pain management and another did not mention headache pain management. They were replaced with two interviews with the next two lowest ILOC scores. Individual excerpts concerning headache pain management were chosen on the basis of their succinct description of frequently expressed issues. Participants often did not remember medication names or expressed confusion about when they took what medication, but they were generally clear about the difference between medication for which they received a prescription and an over-the-counter treatment. Therefore, if the brand name of a prescription drug was mentioned, it was replaced with "prescription medication" and an overthe-counter brand name medication was replaced with "OTC medication." The following are excerpts from the ten interviews that expressed headache pain management.

\section{High ILOC scores}

\section{$I D \# 1, I L O C=50$, depression $=6$}

The participant was a 39-year-old married woman with a postgraduate degree and employed outside the home. She had episodic tension headaches of mild pain lasting two to three days. The frequency of her headaches varied. In the following excerpt, the participant expressed an ability to work despite the headaches.

I have work and I have to go to work. Every time I have a migraine, I can't skip my work. I have to live with it, although thank God, thank God, it is not that severe like some others.

$I D \# 2, I L O C=42$, depression $=11$

This 37-year-old married woman did not complete High School and was employed outside the home. She had migraine without aura with moderate to severe headache pain lasting for two to three days and occurring once a week or less. The following excerpt demonstrated preemptive action when dealing with headache pain.

But on prescription medication, for example, one pill takes away the pain. The next day the headache decreases, but I take another pill so that I won't get the headache again...okay, but I should take my medication so that it won't come back.

$I D \# 3, I L O C=43$, depression $=8$

The participant was a 22-year-old single man, university student with chronic tension headaches. The pain was mild, the duration of headache varied and occurred three to four times a week. Although the student expressed resignation that headache pain was a fact in his life, he also advocated an active and immediate response to headache pain management.

I feel a little bit sad. It is becoming part of my life, but I tried to take it more positively, okay, I can manage with it...If you need fast action, you need to take any medication to stop it [the headache]. You shouldn't wait or say, okay I'll wait now maybe it will go away without any medication.

$I D \# 4, I L O C=49$, depression $=7$

This 55-year-old married woman had a postgraduate degree, and was employed outside the home. She had migraine without aura with mild headache pain. The frequency of the headache varied and lasted for less than $1 \mathrm{~h}$. The participant's statement reflected an organized approach to pain management and daily functioning.

I mean, it has not happened that I missed my office responsibilities or professional responsibilities because of the headache. So this is why I take the medication.

$I D \# 5, I L O C=43$, depression $=6$

The participant was a 36-year-old married woman who completed High School and was employed outside the home. She had episodic tension-type headaches of mild to 
moderate headache pain lasting $1-2 \mathrm{~h}$ and with a varied frequency. The participant expressed the common theme of either self-knowledge, or other forms of information, as a tool for headache pain management.

I don't see doctors usually because I know the cause and the reason [etiology of the headache]. So there is no reason to. I just take a coffee break or I walk outside or something and usually it goes.

\section{Low ILOC scores}

\section{ID \#6, ILOC 10, depression $=34$}

The participant was a 62-year-old single woman who had completed High School and was employed outside the home. She had migraine with aura of moderate to severe pain lasting 2-3 days and occurring once a week or less. This participant had acknowledged a preventive strategy that might give her control over her headache pain, but she stated that her pain did not allow her to apply it.

When I have headaches, I can't manage my everyday activities, my daily life. I would have to sit in a room, and I can't tolerate light at all...Yes, yes, I used to do stretching, and many doctors advised me not to stop because it helps, and I know it helps. I read many articles about it, that it helps. But there is nothing I can do, you know. I stopped because I can't push myself. Maybe no one can understand me except the ones who have migraine with the same intensity as mine. I won't be able to stand anything...The instructor said, "What, one time you come, and the other time you miss?" So I quit because I did not want to hear these comments.

\section{ID \#7, ILOC 14, depression $=36$}

The participant was a 36-year-old married woman with some university education and was a stay at home mother. She had migraine without aura of moderate to severe pain lasting 2-3 days and occurring in clusters. The participant described a situation in which headache pain was unavoidable during the winter and medication ineffective.

Now in winter time I have continual pain because the cold affects my head...Yeah, now, when it's time for my [menstrual] period, also, even if I take medication, I don't feel better, it keeps on hurting for three days.

ID \#8, ILOC 14, depression $=9$

The participant was a 36-year-old married woman who did not complete High School and was a stay at home mother.
She had migraine with aura of moderate to severe pain lasting 2-3 days and occurring 3-4 times a week. Similar to $\# 7$, this participant stated that her medication was ineffective.

I was annoyed by taking medications and I was finding out that I was not feeling better. The headache is still the same... When I go by taxi [and get a headache] there's no way I can function. I won't be able to handle my headache and it will become worse. There is no, there is no way. I have no way to handle it.

$I D \#$, ILOC $=15$, depression $=15$

The participant was a 38-year-old single woman in Graduate School. She had migraine without aura of moderate to severe pain lasting 2-3 days. The frequency of the headache varied. She related a history of experimentation with medication obtained with and without a prescription; therefore, medication misuse and rebound headache were a possibility. This participant described a situation in which pain dominated her life. Her means of managing the pain became another source of pain; thus she was caught in a circular pattern.

I want to take medication, you know, suppositories, I take them. Suppositories are giving me a stomach ulcer and I cannot always take them. I start with my head and end with my stomach...OTC medication causes me the most pain. I do not know why, you know...I keep on living with this headache obsession. It is like, let's assume I went out with my friends and my headache started when I was out, it would change the party or the outing or anything. I would turn it into a drama for them. I do not want to go, I avoid going out with my friends.

$I D \# 10, I L O C=15$, depression $=9$

The participant is a 53-year-old married woman who did not graduate from High School and was employed outside the home. She had migraine without aura of moderate to severe pain lasting 2-3 days and with a varied frequency. The headache started while she was at work and her work supervisor took her to the emergency room. Her disappointment with the medical profession was evident.

Yeah, what is this pain? They [doctors] are not, they are not finding me a solution. Once, there was a doctor, I will not remember his name, in the Emergency Room, he started to ask me questions and so on, he told me that these are psychological things, she needs a psychiatrist, take her to a psychiatrist...I told 
her [supervisor], "Do you see why I do not like to come to the Emergency Room anymore?" Because I already know what my headache needs. It needs peace and locking the door [going to bed]. It [the headache] has no medication [presumably prescription medication]. I take OTC medication, yeah.

Compared to the low ILOC group, the participants in the high ILOC group reported less depression, milder headache pain, shorter durations of pain and had specific strategies to deal with headache pain. The high ILOC group members had different headache types, whereas in the low ILOC group all had migraine headaches with or without aura. In the low ILOC group, indications of depression emerged in the descriptions of immobility in the face of headache pain, whether couched as inability to act or seclusion. Participants \#6 and \#9 most directly expressed the sense of hopelessness and being trapped. In contrast, members of the high ILOC group were generally optimistic and proactive, or were able to function with the headache.

The finding that those in the low ILOC were all women was consistent with studies that have reported a greater prevalence of headache and a greater degree of associated somatizing and depression among women [29, 37-40]. The striking difference between the high and low ILOC groups was the perception of whether or not the pharmaceutical therapies were effective. The interviews revealed that for nine of the ten participants, day-to-day functioning was linked to headache pain management through pharmaceutical intervention. The lengthier durations of pain reported by the low ILOC group suggested that their strategies might be ineffectual.

\section{Discussion}

The aim of the current study was to explore the relationship between headache pain severity and psychosocial variables in a university community in Beirut, Lebanon. We triangulated qualitative and quantitative data to achieve a more holistic picture of the day-to-day management of headache pain. The quantitative data showed that greater headache pain severity was associated with higher levels of depression, whereas this relationship did not hold when controlling for internal locus of control. A higher internal locus of control was associated with lower levels of depression. Therefore, the internal locus of control variable modified the relationship between headache pain severity and depression. Specifically, better coping skills reduced depression among those with more severe headache pain. The results lent support to research that identified locus of control as instrumental in treatment outcomes and headache-related disability [23, 25, 26, 32, 33].
We did not find differences in depression for headache types; therefore our results did not support previous research that observed between headache type differences for psychological symptoms [13, 15]. Also, our results did not support previous findings that a higher self-efficacy was associated with positive headache coping strategies [23]. Nash and colleagues [26] examined psychological contributions to headache-related disability and also found locus of control to be a significant variable, but not self-efficacy. Self-efficacy is defined as the ability to prevent a moderately painful headache and, according to our participants, the ability to prevent headache pain was dependent upon the perception of pharmacologic efficacy. Therefore, the influence of self-efficacy on the association of headache pain severity and depression may have been obscured by attitudes toward medication. Certainly the qualitative descriptions of headache pain management among participants in the low internal locus of control group showed a lack of confidence in pharmacologic therapy and an overlap in self-efficacy and locus of control constructs.

The qualitative data reflected the quantitative findings of a relationship between internal locus of control, coping skills and headache pain severity. In addition, the interviews revealed the central role of the perception of efficacy of pharmacologic intervention. The themes from our interviews that were common to those reported by other qualitative studies on headache were impact on social life, family and friends, pain management strategies and information seeking behavior [1-3, 8]. Pharmacologic therapies were a frequent concern across many of the qualitative studies with Leiper and colleagues [3] reporting that a number of their participants admitted to taking more medication than they should have. Our qualitative findings on the possible misuse of medication together with those of Leiper and colleagues [3] reflected quantitative studies that reported a $25-50 \%$ of noncompliance with prescription medication regimens [41-43].

The strength of the current study was the triangulation of quantitative and qualitative data, for example, the relationship between coping skills and pharmacologic intervention would have been missed if quantitative data solely had been used. Studies have found differences between those who sought treatment for their headaches and those who did not; therefore, the ability to generalize the findings was a limitation to the study due to a selfselection bias [30, 44]. All the participants demonstrated investment in headache pain management and the priority of headache in their lives by virtue of their having been recruited from the university infirmary. Another limitation was the lack of headache research that has been conducted in the Eastern Mediterranean region. The relationship between headache pain and psychosocial factors is doubtless complex and the expression of such informed by 
cultural norms, therefore, comparisons with previous research on locus of control and self-efficacy is problematic. Indeed, cultural norms concerning the expression of locus of control and self-efficacy might have blurred the distinction between the two constructs.

\section{Conclusion}

Given our robust finding that coping style, specifically internal locus of control, moderated the relationship between headache pain severity and depression, we advocate that health professionals consider coping skills as a part of the health education in their treatment plan. The qualitative results regarding the possible misuse of pharmaceuticals indicated that health professionals need to address the appropriate use of prescription and nonprescription medication, particularly in countries lacking firm governmental policies, such as Lebanon, where the problem may be even more widespread.

Acknowledgments We wish to thank all the individuals in Beirut who participated in the study and the University Health Services of the American University of Beirut for their assistance in accessing the institution's database. The research was funded by the Ford Foundation, University Research Board of the American University of Beirut and Three Tees International, Amsterdam.

Conflict of interest None.

\section{References}

1. Belam J, Harris G, Kernick D et al (2005) A qualitative study of migraine involving patient researchers. Br J Gen Pract 55:87-93

2. Cottrell CK, Drew JB, Waller SE et al (2002) Perceptions and needs of patients with migraine: A focus group study. J Fam Pract 51:142-147

3. Leiper DA, Elliott AM, Hannaford PC (2006) Experiences and perceptions of people with headache: a qualitative study. BMC Fam Pract. doi:0.1186/1471-2296-7-27

4. Moloney MF, Strickland OL, DeRossett SE et al (2006) The experiences of midlife women with migraines. J Nurs Scholarsh 38:278-285

5. Peters M, Huijer Abu-Saad H, Vydelingum V et al (2005) The patients' perceptions of migraine and chronic daily headache: a qualitative study. J Headache Pain 6:40-47

6. Ruiz de Velasco I, Gonzalez N, Etxeberria Y et al (2003) Quality of life in migraine patients: a qualitative study. Cephalalgia 23:892-900

7. Slettbakk R, Vaksdal Nilsen C, Malterud K (2006) Coping with headache. Scand J Prim Health Care 24:22-26

8. Tenhunen K, Elander J (2005) A qualitative analysis of psychological processes mediating quality of life impairments in chronic daily headache. J Health Psychol 10:397-407

9. Abramson JH, Hopp C, Epstein LM (1980) Migraine and non-migrainous headaches. A community survey in Jerusalem. J Epidemiol Community Health 34:188-193
10. Deeb M (1997) Beirut: a Health Profile 1984-1994. American University of Beirut Press, Beirut

11. Kececi H, Dener S (2002) Epidemiological and clinical characteristics of migraine in Sivas, Turkey. Headache 42:275-280

12. Abbate-Daga G, Fassino S, Lo Guidice R et al (2007) Anger, depression and personality dimensions in patients with migraine without aura. Psychother Psychosom 76:122-128

13. Baskin SM, Lipchik GL, Smitherman TA (2006) Mood and anxiety disorders in chronic headache. Headache 46(Suppl 3):S76-S87

14. Huber D, Henrich G (2006) Personality traits and stress sensitivity in migraine patients. Behav Med 29:4-13

15. Lampl C, Heuberger B, Haas S et al (2003) Relationship of locus of control in women with migraine and healthy volunteers. Headache 43:878-883

16. Breslau N, Davis GC, Schultz LR et al (1994) Joint 1994 Wolff Award Presentation. Migraine and major depression: a longitudinal study. Headache 34:387-393

17. D'Andrea G, Welch KM, Riddle JM et al (1989) Platelet serotonin metabolism and ultrastructure in migraine. Arch Neurol 46:1187-1189

18. Glover V, Jarman J, Sandler M (1993) Migraine and depression: biological aspects. J Psychiatr Res 27:223-231

19. Miranda H, Ortiz G, Figueroa S et al (2001) Depression scores following migraine treatment in patients attending a specialized center for headache and neurology. Headache 41:680-684

20. Nicholson RA, Houle TT, Rhudy JL et al (2007) Psychological risk factors in headache. Headache 47:413-426

21. Sternbach RA, Dalessio DJ, Kunzel M et al (1980) MMPI patterns in common headache disorders. Headache 20:311-315

22. Ford S, Calhoun A, Kahn K et al (2008) Predictors of disability in migraineurs referred to a tertiary clinic: Neck pain, headache characteristics, and coping behaviors. Headache 48:523-528

23. French DJ, Holroyd KA, Pinell C et al (2000) Perceived selfefficacy and headache-related disability. Headache 40:647-656

24. Marlowe N (1998) Self-efficacy moderates the impact of stressful event on headache. Headache 38:662-667

25. Martin MJ, Holroyd KA, Penzien DB (1990) The headachespecific locus of control scale: adaptation to recurrent headaches. Headache 30:729-734

26. Nash JM, Williams DM, Nicholson R et al (2006) The contribution of pain-related anxiety to disability from headache. J Behav Med 29:61-67

27. O'Hea EL, Boudreaux ED, Jeffries SK et al (2004) Stage of change movement across three health behaviors: the role of selfefficacy. Am J Health Promot 19:94-102

28. Rollnik JD, Karst M, Fink F et al (2001) Coping strategies in episodic and chronic tension-type headache. Headache 41:297302

29. Rollnik JD, Karst M, Piepenbrock S et al (2003) Gender differences in coping with tension-type headaches. Eur Neurol 50:7377

30. Skomo ML, Desselle SP, Berdine HJ (2006) Factors influencing migraineurs-consulting behavior in a university population. Headache 46:742-749

31. Kraft CA, Lumley MA, D'Souza PJ et al (2008) Emotional approach coping and self-efficacy moderate the effects of written emotional disclosure and relaxation training for people with migraine headaches. Br J Health Psychol 13:67-71

32. Hudzynski L, Levenson H (1985) Biofeedback behavioral treatment of headaches with locus of control pain analysis: a 20month retrospective study. Headache 25:380-386

33. Scharff L, Turk DC, Marcus DA (1995) The relationship of locus of control and psychosocial-behavioral response in chronic headache. Headache 35:527-533 
34. Beck AT, Ward CH, Mendelson M et al (1961) An inventory for measuring depression. Arch Gen Psychiatry 4:561-571

35. Farhood LF (1999) Testing a model of family stress and coping based on war and non-war stressors, family resources and coping among Lebanese families. Arch Psychiatr Nurs 13:192-203

36. Headache Classification Committee of the International Headache Society (2004) The international classification of headache disorders 2nd edn. Cephalalgia 24(Suppl 1):S8-S160

37. Celentano DD, Linet MS, Stewart WF (1990) Gender differences in the experience of headache. Soc Sci Med 30:1289-1295

38. Gilbar O, Bazak Y, Harel Y (1998) Gender, primary headache, and psychological distress. Headache 38:31-34

39. Labbe EE, Murphy L, O'Brien C (1997) Psychological factors and prediction of headaches in college adults. Headache 37:1-5

40. Stovner LJ, Hagen K, Jensen R et al (2007) The global burden of headache: a documentation of headache prevalence and disability worldwide. Cephalalagia 27:193-210
41. Linde M, Jonsson P, Hedenrud T (2008) Influence of disease features on adherence to prophylactic migraine medication. Acta Neurol Scand. doi:10.111/j.1600-0404.2008.01042x

42. Rains JC, Lipchik GL, Penzien DB (2006) Behavioral facilitation of medical treatment for headache-Part I: review of headache treatment compliance. Headache 46:1387-1394

43. Rains JC, Penzien DB, Lipchik GL (2006) Behavioral facilitation of medical treatment for headache-Part II: theoretical models, behavioral strategies for improving adherence. Headache 46:1395-1403

44. Rokicki LA, Holroyd KA (1994) Factors influencing treatmentseeking behavior in problem headache sufferers. Headache $34: 429-434$ 